\title{
SuomiNet: A Real-Time National GPS Network for Atmospheric Research and Education
}

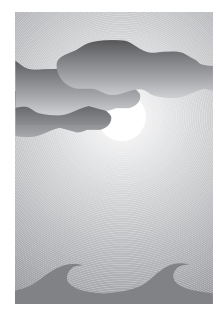

\author{
Randolph H. Ware, ${ }^{*}$ David W. Fulker, ${ }^{+}$Seth A. Stein," David N. Anderson, ${ }^{@}$ \\ Susan K. Avery, ${ }^{@}$ Richard D. Clark, ${ }^{\&}$ Kelvin K. Droegemeier, ${ }^{* *}$ Joachim P. Kuettner, ${ }^{++}$ \\ J. Bernard Minster,\#\# and Soroosh Sorooshian ${ }^{\circledR}$
}

\begin{abstract}
"SuomiNet," a university-based, real-time, national Global Positioning System (GPS) network, is being developed for atmospheric research and education with funding from the National Science Foundation and with cost share from collaborating universities. The network, named to honor meteorological satellite pioneer Verner Suomi, will exploit the recently shown ability of ground-based GPS receivers to make thousands of accurate upper- and lower-atmospheric measurements per day. Phase delays induced in GPS signals by the ionosphere and neutral atmosphere can be measured with high precision simultaneously along a dozen or so GPS ray paths in the field of view. These delays can be converted into integrated water vapor (if surface pressure data or estimates are available) and total electron content (TEC), along each GPS ray path. The resulting continuous, accurate, all-weather, real-time GPS moisture data will help advance university research in mesoscale modeling and data assimilation, severe weather, precipitation, cloud dynamics, regional climate, and hydrology. Similarly, continuous, accurate, all-weather, real-time TEC data have applications in modeling and prediction of severe terrestrial and space weather, detection and forecasting of low-altitude ionospheric scintillation activity and geomagnetic storm effects at ionospheric midlatitudes, and detection of ionospheric effects induced by a variety of geophysical events. SuomiNet data also have potential applications in coastal meteorology, providing ground truth for satellite radiometry, and detection of scintillation associated with atmospheric turbulence in the lower troposphere. The goal of SuomiNet is to make large amounts of spatially and temporally dense GPS-sensed atmospheric data widely available in real time, for academic research and education. Information on participation in SuomiNet is available via www.unidata.ucar.edu/suominet.
\end{abstract}

*GPS Science and Technology Program, University Corporation for Atmospheric Research Office of Programs, Boulder, Colorado. +Unidata, UCAR Office of Programs, Boulder, Colorado.

"University Navstar Consortium, Boulder, Colorado, and Northwestern University, Evanston, Illinois.

${ }^{\circledR}$ Cooperative Institute for Research in Environmental Sciences, University of Colorado, Boulder, Colorado.

\&Millersville University, Millersville, Pennsylvania.

**Center for the Analysis and Prediction of Storms, and University of Oklahoma, Norman, Oklahoma.

${ }^{++}$University Corporation for Atmospheric Research, Boulder, Colorado.

\#"University of California, San Diego, San Diego, California.

${ }^{\circledR}$ Department of Hydrology, The University of Arizona, Tucson, Arizona

Corresponding author address: Dr. Randolph H. Ware, UCAR GPS Science and Technology Program, UCAR, P.O. Box 3000, Boulder, CO 80307-3000.

E-mail: ware@ucar.edu

In final form 17 September 1999.

(C)2000 American Meteorological Society

\section{Introduction}

The authors, collaborating universities, and the National Science Foundation (NSF) are establishing SuomiNet, a national Global Positioning System (GPS) network designed for real-time atmospheric remote sensing. SuomiNet will augment an existing GPS network located primarily in the central United States and including approximately 40 federal and university sites (www.fsl.noaa.gov and www.gst.ucar.edu/gpsrg/ realtime.html). SuomiNet will use well-established Internet Data Distribution (IDD) software and protocols to coordinate network sensors and distribute its data in real time (IDD has evolved over more than a decade to provide real-time atmospheric data to university users). SuomiNet will demonstrate the innovative concept of a university-based national geophysical instrument providing critical real-time atmospheric 
data for research and education. Upper- and lower-atmospheric sensing with ground-based GPS receivers is illustrated in Fig. 1.

SuomiNet data are relevant to the U.S. Weather Research Program (USWRP) (uswrp.mmm.ucar.edu/ uswrp), to the international Global Energy and Water Cycle Experiment (GEWEX) (www.cais.com/gewex/ projects.html), and to the National Space Weather Program (NSWP) (www.ofcm.gov/nswp-ip/text/ cover.htm). The continuous, all-weather, real-time GPS moisture data will help advance university research in mesoscale modeling and data assimilation, severe weather, precipitation, cloud dynamics, regional climate, and hydrology. These topics are central to the USWRP and GEWEX. In addition, total electron content (TEC) and ionospheric scintillation data derived from GPS signal phase and amplitude will help universities and research institutions (hereafter called simply "universities") address overarching, fundamental research topics. These topics, all priorities of the NSWP, include the processes that govern the spatial distribution of ionization; the evolution of ionospheric irregularities and scintillation; thermospheric dynamics and its coupling to the ionosphere; and validation, testing, and continued development of research models and numerical methods.
SuomiNet addresses the recommendations of the National Research Council (1998) Board on Atmospheric Sciences and Climate. The board's two highest priority recommendations are to "improve observation capabilities" and "develop new observation capabilities."

From an educational perspective, SuomiNet will place state-of-the-art GPS equipment, data, and processing methods in the hands of a large number of university departments, faculty, and students. It is here, in the university setting, where the tremendous potential of GPS in atmospheric research and education can be most effectively realized. The impact of these new data and observation methods on the atmospheric sciences may be dramatic, comparable to the impact GPS data have had in a few short years on the solid-earth sciences (Stein et al. 1998).

SuomiNet builds on the expertise of University Corporation for Atmospheric Research (UCAR) programs including the GPS Science and Technology (GST) program (GPS-related atmospheric science), Unidata (real-time distribution of meteorological data to universities), and the University Navstar Consortium (UNAVCO) Facility (developing, deploying, and operating GPS networks).

\section{Atmospheric Sensing with Ground-Based GPS}

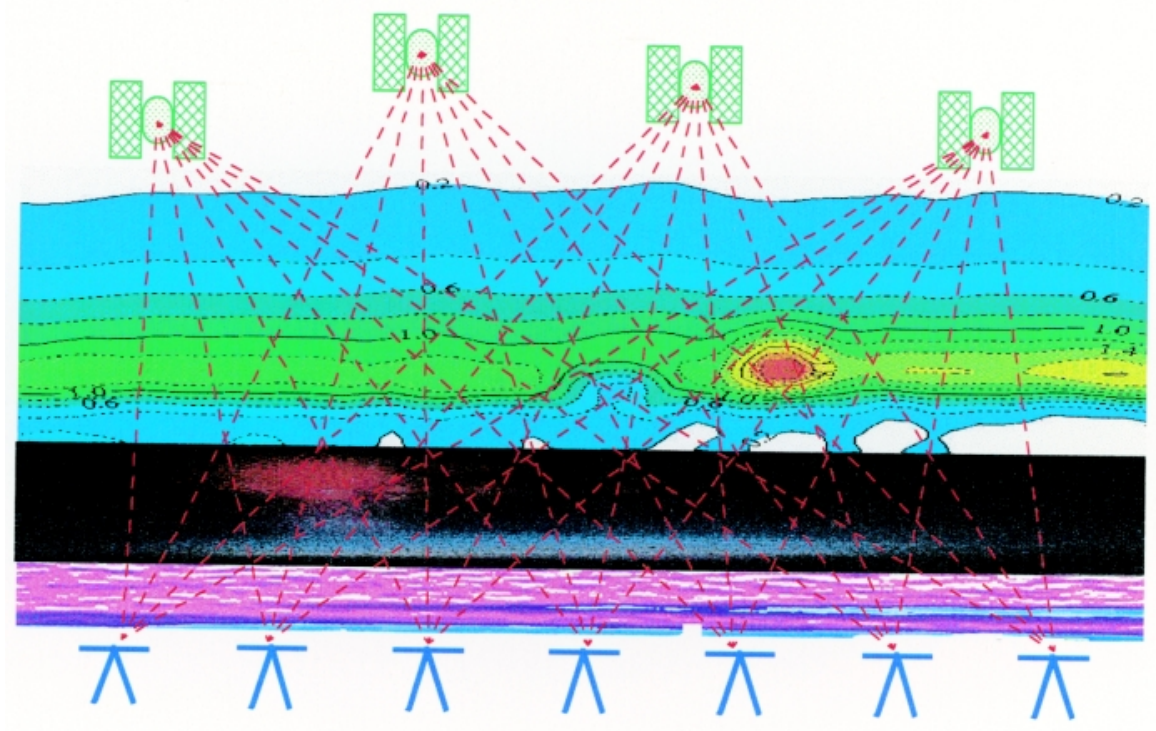

FIG. 1. A variety of useful information regarding upper- and lower-atmospheric structure and dynamics can be derived from GPS signal phase and amplitude data. In this illustration, the troposphere is depicted by a lidar scan of tropospheric water vapor, the stratosphere and mesosphere by a photo of a red jet and blue sprite (elf.gi.alaska.edu), and the ionosphere by an ionospheric model (janus.nwra.com/nwra/tomr2j.gif).

\section{Research applications}

The atmosphere is illuminated with 1.6- and 1.2-GHz (L1 and L2) signals transmitted by the 24 GPS satellites. Phases of signals from a dozen or so of these satellites can be simultaneously observed with millimeter precision during all weather conditions, using commercial GPS receivers. Observing from sea level, the lower and upper atmosphere induce GPS signal phase path delays of several meters or more. The key to SuomiNet-enabled research (and education) is to view these delays not as signal propagation errors but as atmospheric information. In the upper atmosphere, TEC along each GPS ray path can be measured by combining L1 and L2 phase observations. 
In the lower atmosphere, dry air, water vapor, and hydrometeors induce delays in GPS signals. However, effects generated by hydrometeors are relatively small (Solheim et al. 1999). As a result, water vapor-integrated along each GPS signal path - can be inferred if observed or estimated surface pressure is available. Accurate geodetic coordinates also can be derived from these data, as has been amply demonstrated (Stein et al. 1998).

Universities have registered to establish the SuomiNet sites shown in Fig. 2. All sites are registered for atmospheric research applications, and approximately $60 \%$ are registered also for geodetic applications. Other research interests include hydrology and oceanography. At each SuomiNet site, participating universities will install and operate a standardized system including a dual-frequency GPS receiver, surface meteorological sensors, and a computer connected to the Internet and configured with IDD software. Participants interested in geodetic applications will install their GPS equipment in appropriate locations on stable geodetic monuments. Technical assistance regarding GPS equipment, monuments, and IDD will be provided by the UNAVCO Facility, Unidata, and GST.

SuomiNet will provide raw GPS and surface meteorological data, tropospheric and ionospheric delays, 2D water vapor, and $2 \mathrm{D}$ TEC data to universities in real time, as illustrated in Fig. 3.

University investigators, through independent research programs, will be able to assimilate these data into models to provide real-time 3D water vapor and electron densities, and to enhance space weather and hydrological cycle modeling. GPS, surface meteorological, and other data observed at SuomiNet sites will also be distributed in real time using IDD software and protocols (www.unidata.ucar.edu). IDD is designed to allow universities to request delivery of specific datasets directly to their computers, as soon as they are available (Domenico et al. 1994).

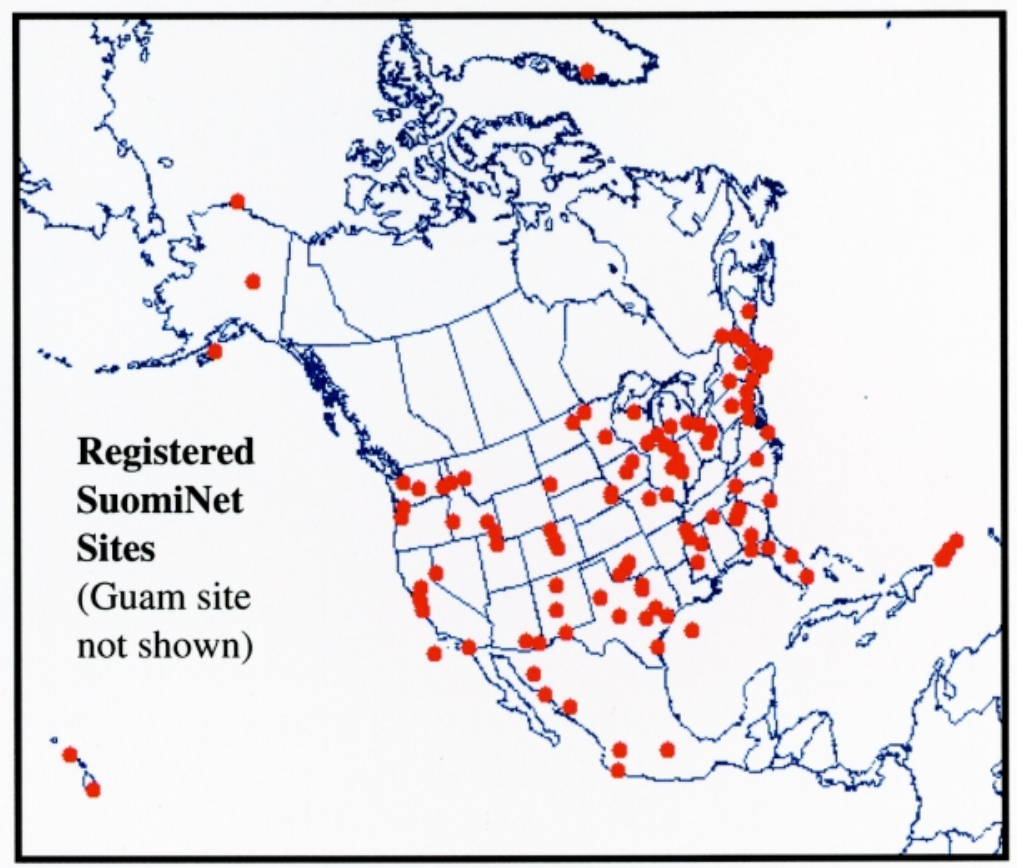

FIG. 2. Universities have registered the indicated site locations for participation in SuomiNet. For prospective participants, information and online registration are available via www.unidata.ucar.edu/souminet.

\section{Internet Accessible Data}

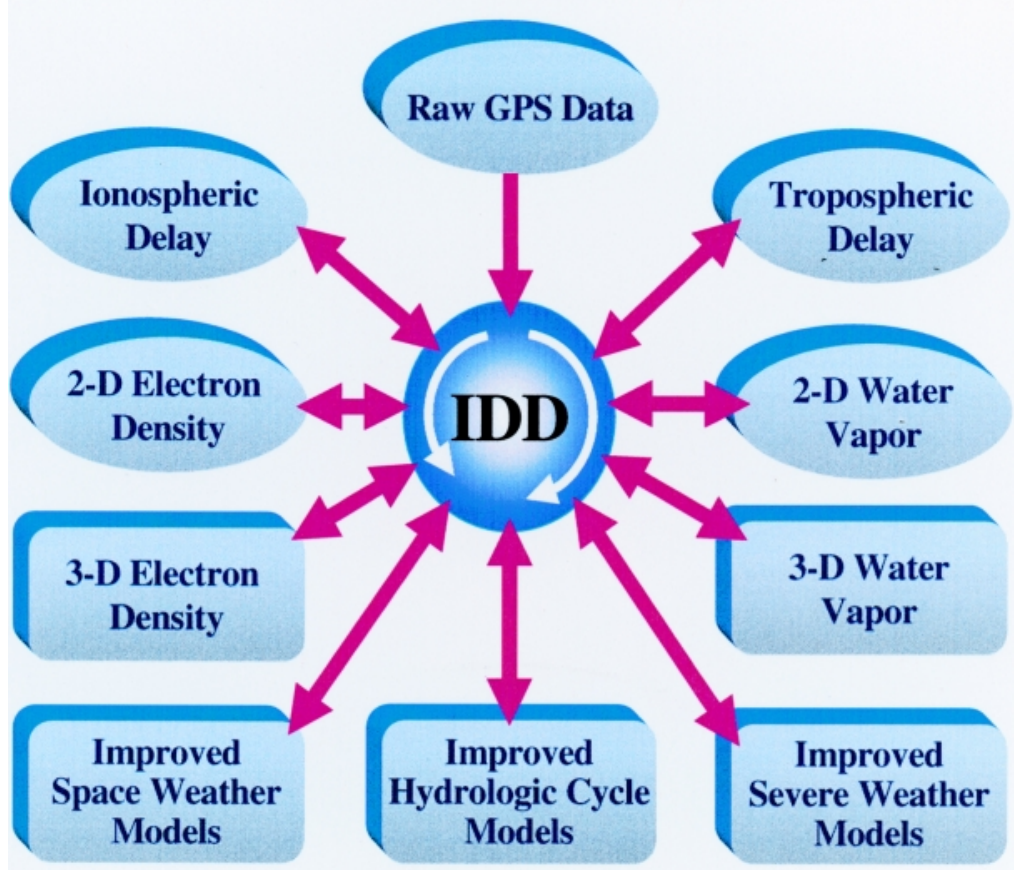

FIG. 3. SuomiNet data and products to be provided to universities in real time are represented by the oval symbols. Data products that are expected to be derived from SuomiNet data through independent university research programs are represented by rectangular symbols. 
An IDD characteristic that will extend to SuomiNet is that the data streams are accessible at no cost (either for data or software) to any college or university, large or small. The system design also allows any participant to inject additional observations or derived products into the IDD for delivery to other interested members of the network. Coordinated real-time control of GPS and other SuomiNet equipment, such as sampling frequency, data type and format, data latency, and other sensor parameters will be provided via IDD. Thus, SuomiNet will demonstrate the concept of a national geophysical instrument coordinated via the Internet. Once demonstrated, this concept has the potential to address many additional research and education objectives, as described later.

\section{a. Water vapor in atmospheric processes}

Water in its three phases has a profound influence on weather and climate. Water vapor, the means by which moisture and latent heat are transported, plays a fundamental role in atmospheric processes that act over a wide range of spatial and temporal scales. Improved understanding of water vapor and its role in weather and climate is a major objective of national and international research programs, including USWRP and GEWEX.

It is widely recognized that moisture fields are inadequately defined in global, regional, and local weather analysis and forecasting. This inadequacy stems from the sparsity of water vapor observations, combined with the high spatial and temporal variability of moisture fields (Trenberth and Guillemot 1996). Traditional water vapor observing systems include radiosondes, surface-based humidity sensors, surface and satellite-based radiometers, and research aircraft. Ground-based GPS sensing of atmospheric moisture, demonstrated by university researchers (Bevis et al. 1992; Rocken et al. 1993), is complementary to these traditional systems, providing autonomous, frequent, economical, and accurate moisture data that are unaffected by weather conditions or time of day.

Timely and accurate moisture data are needed to advance mesoscale modeling research (e.g., McPherson et al. 1997) and to improve the quality of short-term cloud and precipitation forecasts (Emanuel et al. 1995). Universities at the leading edge of this research are running real-time mesoscale models for numerical weather prediction (Mass and Kuo 1998). Included are The Pennsylvania State University (Warner and Seaman 1990), Colorado State University (Cotton et al. 1994), the University of Utah (Horel and Gibson
1994), the University of Washington, North Carolina State University, The University of Wisconsin, the University of Michigan, the University of Arizona, the University of Oklahoma, and other universities. For example, the Center for Analysis and Prediction of Storms at the University of Oklahoma produces realtime mesoscale (10-100 km) and storm-scale (1$10 \mathrm{~km}$ ) forecasts (Xue et al. 1996; Carpenter et al. 1998). This group is using real-time weather radar [Next Generation Weather Radar (NEXRAD)] data to improve prediction of severe storms (Droegemeier et al. 1999). They expect that assimilation of highresolution moisture field data derived from GPS will allow modeling of convection before it is detected by radar reflection from hydrometeors (K. Droegemeier 1998, personal communication). An example of realtime column water vapor or "precipitable water" $(\mathrm{PW})$ estimated from GPS network data in the south-central United States is shown in Fig. 4.

GPS-sensed PW data can be used to improve storm system analysis (Rocken et al. 1995; Businger et al. 1996). In addition, improved vertical structure of water vapor and short-term precipitation forecasts can be obtained by assimilating surface humidity and PW data into mesoscale models (Kuo et al. 1996). Park and Droegemeier (1996) showed that simulations of thunderstorms can be quite sensitive to the distribution of water vapor in their near environment. Crook (1996) studied the sensitivity of thunderstorm initiation in northeastern Colorado to the distribution of temperature and moisture in the atmospheric boundary layer. Utilizing the fact that water vapor $2 \mathrm{~m}$ above the ground is relatively well specified by existing sensor networks, the study examined variations from these values as a function of height within the boundary layer. The finding was that thunderstorm initiation is most sensitive to the temperature profile while thunderstorm strength is most sensitive to water vapor content. Hence, better measurements of the entire water vapor burden, a SuomiNet data product, are likely to yield better thunderstorm forecasts.

Water vapor is a greenhouse gas that plays a critical role in the global climate system (Starr and Melfi 1991). This role is not restricted to absorbing and radiating energy from the sun (Stokes and Schwartz 1994), but includes the role of water vapor on the formation of clouds and aerosols, and on the chemistry of the lower atmosphere. SuomiNet will provide accurate real-time water vapor data on a regional and continental scale that can make a significant contribution to the USWRP and GEWEX. It will also allow the 
United States to join with other countries establishing GPS networks for atmospheric sensing (see section 4) to create a global real-time GPS network for atmospheric research and education.

\section{b. Sensing atmospheric moisture with GPS}

There are several approaches to GPS sensing of atmospheric water vapor from the ground. The first to be developed (Bevis et al. 1992) uses standard space geodetic techniques (Dixon 1991; Hager et al. 1991; Segall and Davis 1997) to estimate the 2 to 3-m zenith phase delay induced in GPS signals by the neutral atmosphere. Residual signal delays to each satellite are mapped as the cosecant of the satellite elevation angle (Niell 1996), based on the assumption that the atmosphere is azimuthally homogeneous. This gives an average zenith delay, from which the hydrostatic or "dry" component, estimated from surface pressure, is subtracted. Precipitable water is calculated as the product of the zenith delay and a conversion factor (Bevis et al. 1994). The accuracy of GPS-sensed PW by this method is better than $2 \mathrm{~mm}$ (Rocken et al. 1993, 1997a; Duan et al. 1996; Fang et al. 1998).

The assumption of azimuthal symmetry (Davis et al. 1993; Elosegui et al. 1998) limits the accuracy and spatial resolution of GPS-sensed PW. Higher spatial resolution can be obtained by solving for the integrated water vapor or "slant water" (SW) along each GPS ray path. The SW is obtained by solving for the total slant delay along each ray path, and then subtracting the dry component of the slant delay. The dry slant delay can be estimated from surface pressure measurements or from three-dimensional numerical weather models (Chen and Herring 1997). The spatial coverage that can be achieved through GPS observations of SW is shown in Fig. 5.

The increased spatial resolution of SW sensing is based on the ability of commercial GPS receivers to track 10 or so GPS satellites at any moment in time.
The tracking can continue as low as a half a degree below the horizon as a result of refractive bending (Ware et al. 1997). At zero degree elevation, a GPS ray reaches an altitude of $2 \mathrm{~km}$ at a distance of about $200 \mathrm{~km}$ from a ground-based GPS antenna. A comparison of SW sensed by GPS and by water vapor radiometers pointed sequentially along the line of sight to each GPS satellite is shown in Fig. 6.

The high-frequency variations in the GPS-sensed SW data are attributed to small-scale structures in the moisture field. These small-scale structures are not observed in the radiometer data, which are averaged over a $5^{\circ}$ field of view at 8 -min intervals. Comparison of GPS and pointed radiometer data determined GPSsensed SW noise levels at $1.4 \mathrm{~mm}$ rms near $10^{\circ}$ elevation angle, decreasing to $0.2 \mathrm{~mm}$ rms near the zenith (Braun et al. 2000, manuscript submitted to Radio Sci.).

Though much remains to be learned, the applicability of GPS sensing to the measurement of atmospheric moisture has already been demonstrated over areas that are largely distinct from the planned 


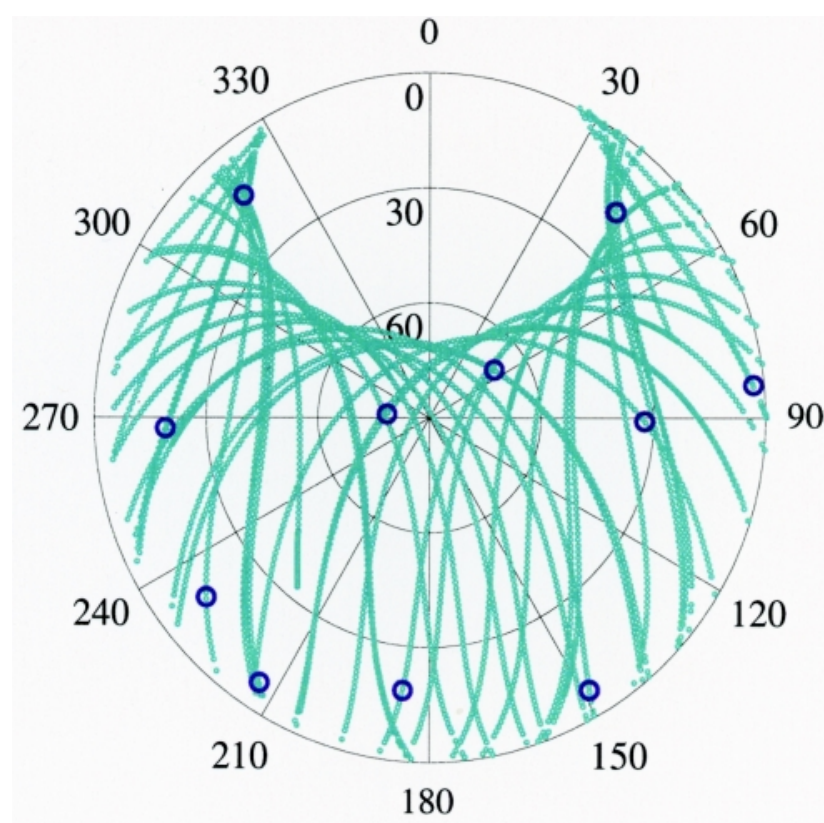

FIG. 5. GPS satellite elevation and azimuth tracks ("sky plots") observed near Boulder, CO, during one day (light blue curves) and at one point in time (blue circles). A GPS receiver is located at the center of the plot. Tracking is blocked by mountains to the west (below $3^{\circ}$ ), but reaches minus $0.5^{\circ}$ elevation to the east over the plains. SW ("slant water," integrated water vapor along a slant path) can be estimated simultaneously along the ray paths to each satellite in view.

SuomiNet coverage. For example, Naito et al. (1998) describe the Japanese 5-yr, 10-agency, GPS Meteorology Program. The program uses data from the 1000-site Japanese GPS network, originally established for earthquake research and hazard mitigation. Data from this network are now being used also for climate and numerical weather prediction studies (Tsuda et al. 2000a). Goals include use of GPS-sensed SW data to improve mesoscale modeling and forecast-

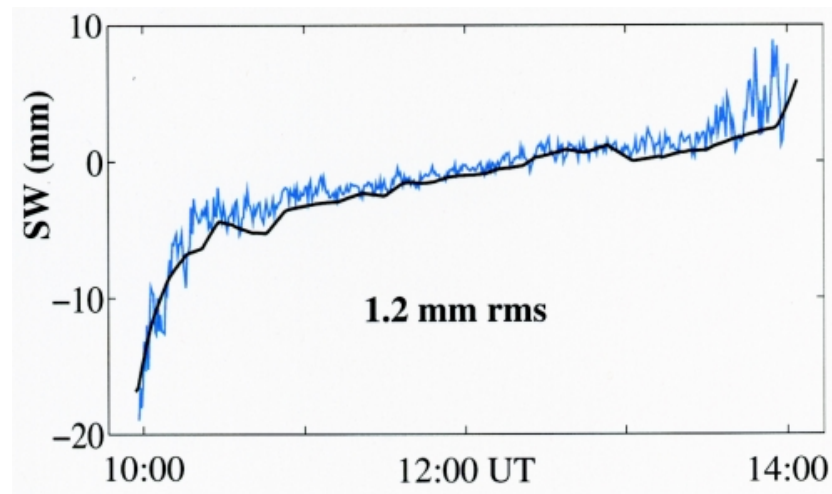

FIG. 6. GPS (jagged blue) and pointed radiometer (smooth black) sensed SW ("slant water," integrated water vapor along a GPS ray path) and their rms agreement (Ware et al. 1997). ing, and use of the resulting analysis to improve GPS survey accuracy (Iwabuchi et al. 1998, manuscript submitted to J. Meteor. Soc. Japan; Ohtani and Naito 1999, manuscript submitted to J. Meteor. Soc. Japan). Examples of increased variability in GPS slant delays observed by the Japanese network during a typhoon, presumably from increased water vapor variability, are shown in Fig. 7.

GPS observations can also be used to measure the velocity of strong refractive features moving above a network. For example, Herring and Shimada (1998) used slant delay time series from the Japanese network to estimate the velocity and height of "water vapor winds." Estimation of water vapor winds by this method is complementary to established techniques that extract atmospheric motion vectors from satellite cloud and moisture images (Holmlund 1998). Large improvements are expected when high-resolution wind and moisture field data are assimilated into mesoscale models (Y.-H. Kuo 1998, personal communication).

Four-dimensional characterization of atmospheric refractivity using GPS-sensed slant delays was recently demonstrated by Elosegui et al. (1999, manuscript submitted to Geophys. Res. Lett.). Another approach uses data from an array of low-cost, single-frequency (L1) GPS receivers spaced by $1-2 \mathrm{~km}$ to characterize four-dimensional water vapor fields (Meertens et al. 1998; Braun et al. 1999, manuscript in preparation; www.gst.ucar.edu/gpsrg/arm.pdf). These studies demonstrate the potential for water vapor tomography using slant path data from closely spaced GPS arrays. The practicality of using single-frequency receivers is enhanced by proximate dual-frequency receivers and by good TEC prediction models. SuomiNet is expected to improve both factors.

Amplitude data from ground-based GPS receivers may be useful in studies of atmospheric turbulence. Minami et al. (1999, manuscript submitted to $J$. Geophys. Res.) report observations of enhanced scintillation in GPS signals when both the atmospheric turbulence intensity and water vapor mixing ratio are large. In this study, the detailed structure of meteorological disturbances was determined using boundary layer radar, radiosonde, laser ceilometer, and GPS data. The relationship between GPS amplitude scintillation and atmospheric turbulence can be further studied using SuomiNet.

Assimilation of SW data in models can simultaneously constrain the integrated water vapor along a dozen or so GPS ray paths. A simulation experiment 
demonstrated that a network of GPS stations with 40-km spacing can be used to determine atmospheric water vapor structure with high resolution (MacDonald and Xie 2000). Additional research is needed to fully utilize GPS moisture data in mesoscale modeling and prediction (e.g., Gou et al. 2000; Fang et al. 1998). However, assimilation operators for GPS-sensed SW and water vapor wind data must first be developed and tested. The most appropriate place for this to occur is in university settings, at the forefront of real-time mesoscale modeling and data assimilation research. The availability to university researchers of thousands of GPS slant delay observations per hour on a national scale is expected to stimulate significant advancements in mesoscale analysis and prediction.

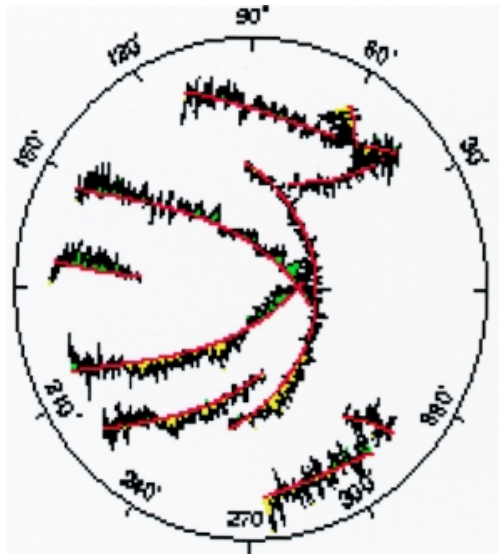

Calm, 5.7 mm rms

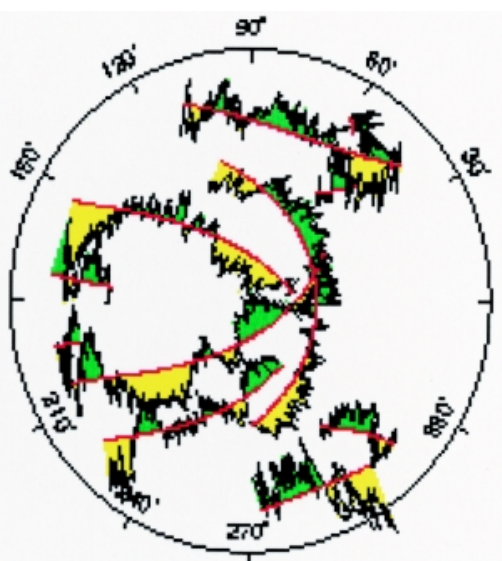

Typhoon, $11.1 \mathrm{~mm}$ rms

FIG. 7. Four hours of atmospheric slant delays plotted vs the observed GPS satellite azimuth and elevation angles (Herring and Shimada 1998) as viewed by a GPS receiver located at the center of the "sky plot." Green (positive) and yellow (negative) perturbations are plotted perpendicular to the satellite trajectories (red). The larger slant delay variations seen during typhoon conditions are attributed primarily to changes in water vapor.

\section{c. Sensing the ionosphere with GPS}

SuomiNet data promise to have an even greater impact on the ionospheric research than on meteorology, since the ionosphere is a very data sparse region compared to the neutral atmosphere. One of the primary goals of the NSWP is the development of global ionospheric models that can assimilate all types of ground- and space-based observations. GPS provides a timely and cost-effective method of obtaining ionospheric data. Based on the frequency dependence of ionospheric delays, integrated TEC along the ray path from each GPS satellite in view can be estimated from dual-frequency GPS data (Ho et al. 1996). Large numbers of real-time TEC observations are the datasets needed for the three-dimensional ionospheric data assimilation and modeling. This capability is currently under development at several universities. The U.S. military is assisting by funding the development of a global ionospheric model. The joint military research laboratory-university project began in April 1999 and will continue for five years.

Hemispheric and global mapping of vertically averaged TEC has been demonstrated using GPS data from the International GPS Service (IGS) network (igscb/jpl.nasa.gov) including approximately 200 GPS stations distributed worldwide (Zumberge et al. 1997). These two-dimensional horizontal maps are made using a Kalman filter and a mapping function to convert slant to vertical measurements (e.g., Wilson et al. 1995; Ho et al. 1996). More complex modeling of the ionosphere has been demonstrated using IGS data and a stochastic tomographic approach with a two-layer model (Juan et al. 1997). The model characterized lowresolution time varying three-dimensional TEC structure on a global scale. A similar approach provides real-time maps of global TEC, plus one- and two-day predictions via the Internet (www.cx.unibe.ch/aiub/ ionosphere.html). SuomiNet will contribute highresolution TEC data to improve the fidelity of ionospheric mapping, modeling, and prediction over the United States. An example of a real-time TEC map derived from ground-based GPS data is shown in Fig. 8.

The potential for ionospheric modeling is much greater if space-based GPS occultation data are also available. For example, GPS observations from low earth orbit (e.g., Ware et al. 1996; Schreiner et al. 1998) were used with ground-based IGS data to model the temporal evolution of three-dimensional electron density on a global scale during ionospheric storms (Hernandez-Pajares et al. 1998). The tomographic model was solved with $1-\mathrm{h}, 10^{\circ} \times 10^{\circ}$, eight-layer resolution. For each storm, 1 million delays and 400 occultations were assimilated to solve for 3000 unknowns. Results were verified using the International Reference Ionosphere and ionosonde data. Howe et al. (1998) simulated the use of ground- and space-based GPS data in four-dimensional ionospheric modeling, with resulting large improvements in model resolution and accuracy. 
Ionospheric scintillation occurs in equatorial, midlatitude, and auroral zones, induced by geomagnetic storms, solar conditions, Rayleigh-Taylor instabilities, and other known and unknown mechanisms (e.g., Fremouw et al. 1978; Basu and Basu 1981; Yeh and Liu 1982; Aarons 1997). SuomiNet sites located in each of these zones will be able to measure variations in GPS phase and amplitude induced by ionospheric scintillation at sampling intervals of $1 \mathrm{~s}$ or less. For example, a SuomiNet site at Guam is well positioned to study the onset of equatorial scintillation activity. A strong, enhanced upward ExB (cross product of electric and magnetic field vectors) drift is required to create the ambient ionospheric conditions responsible for this activity. The enhanced ExB drift causes TEC to decrease dramatically. The GPS receiver at Guam (or any other GPS receiver situated near the magnetic equator) can measure this decrease (e.g., Kelley et al. 1996; Musman et al. 1997). An hour and a half later, small-scale plasma density irregularities are expected to form. These irregularities can be detected by the same GPS receiver.

\section{Real-Time GPS Sensing of Ionospheric TEC}

\section{8/30/99, 17:30 UT}

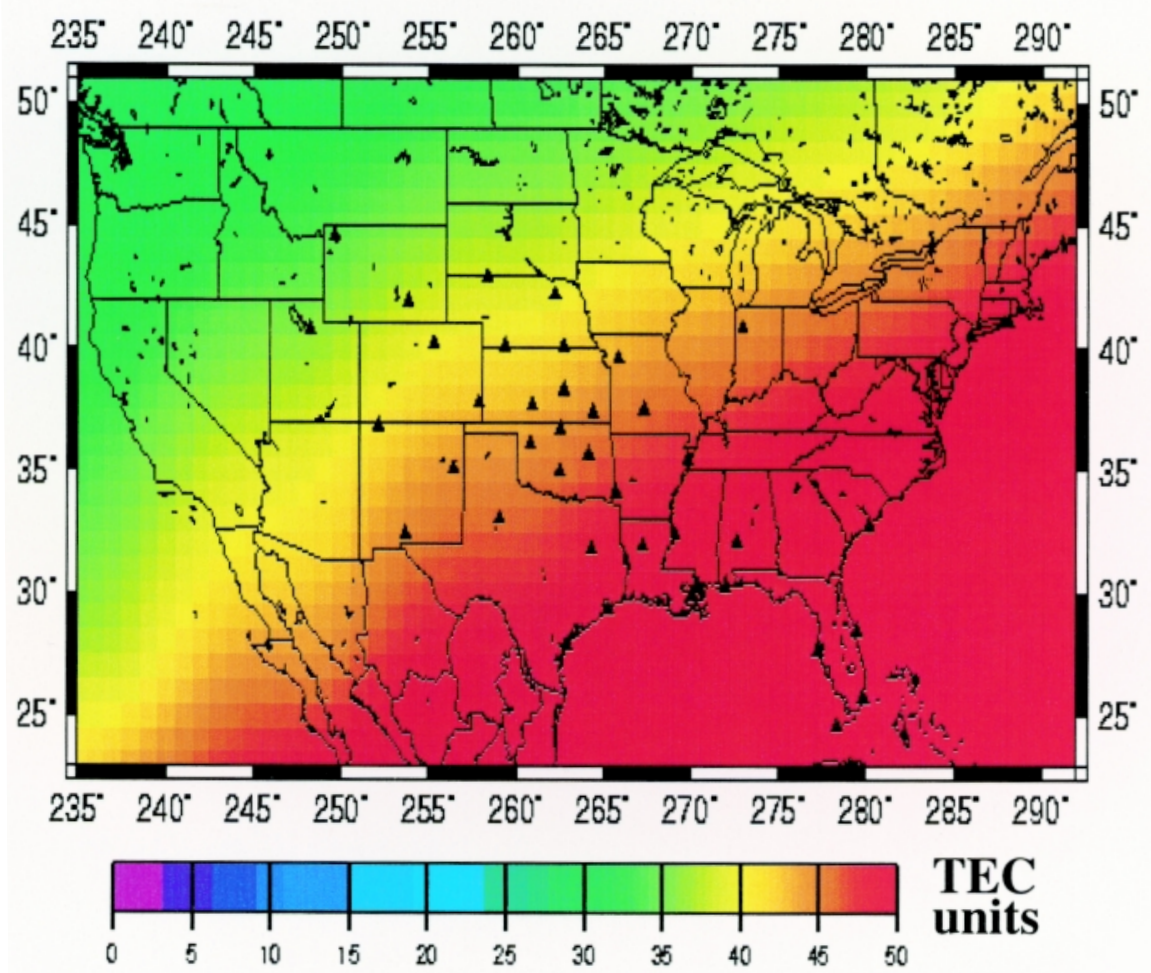

FIG. 8. TEC estimated from GPS measurements (www-dd.fsl.noaa.gov/gps.html) in the south-central United States, as posted every $30 \mathrm{~min}$ (www.gst.ucar.edu/gpsrg/realtime.html). GPS sites are shown as black triangles.
During geomagnetic storms, SuomiNet TEC observations could be used to determine whether the midlatitude ionospheric response is generated by the penetration of high-latitude electric fields (ExB drift) or to the propagation of traveling ionospheric disturbances (TIDs) initiated by traveling atmospheric disturbances (TADs) (e.g., Beach et al. 1997; Taylor et al. 1998). For example, two-dimensional maps of TEC perturbations derived from data observed at $900 \mathrm{GPS}$ sites in Japan showed the spatial structure, time evolution, and velocity (tens to hundreds of meters per second) of electron density structures with $0.15^{\circ}$ latitude and longitude resolution (Saito et al. 1998). Similar analyses could be used to relate the occurrence of gravity waves in the lower atmosphere associated with storms, topography, and jet streams (Fritts and Nastrom 1992; Nastrom and Fritts 1992), as observed in rocketsonde (Tsuda et al. 1994), radar (Murayama et al. 1994), lidar (Whiteway and Carswell 1995), and GPS occultation data (Tsuda et al. 2000b).

The effects of ExB drift are felt simultaneously at all latitudes while the TIDs propagate from high to low latitudes with a characteristic velocity. This velocity can be uniquely determined, using data from the midlatitude chain of SuomiNet receivers. Another question related to geomagnetic storms is the longitudinal extent of the "positive phase" of ionospheric storms, defined as the enhancement in electron density at local sunset on the first day of the storm. The open question is whether this enhancement exists over a wide longitudinal sector, as the earth rotates through the sunset terminator. The large east-west chain of SuomiNet receivers will be able to answer this question unequivocally.

Because of the phenomenal growth of GPS, the large and growing numbers of regional and global GPS networks, and the development of global GPS occultation capability, (Rocken et al. 1997b) the infrastructure for fully three-dimensional ionospheric tomography is be- 
coming established (e.g., Rius et al. 1997, 1998). SuomiNet will make a significant contribution to this infrastructure, providing thousands of TEC measurements hourly over the United States. University researchers can assimilate these data into high-resolution regional models. SuomiNet data, and data from similar networks in Japan (mekira.gsi-mc.go.jp), Europe (www.cx.unibe.ch/aiub/ionosphere/html; www.ieec.fcr.es/gps/intro.html), and elsewhere [e.g., IGS: jgscb.jpl.nasa.gov; China: Li and Mao (1998); Taiwan: Liou (2000)], combined with thousands of GPS occultation observations (e.g., www.cosmic.ucar.edu), will simulate the rapid development of global-scale ionosphere models.

\section{d. Additional applications}

A key to understanding the earth system is learning how and why various geophysical quantities vary in space and time. As a result, considerable attention has been directed toward building networks of instruments to make these observations. Such networks include weather stations, seismometers, strainmeters, tide gauges, and a variety of other instruments. Historically, advances in instruments have provided the data that drove dramatic advances in understanding the phenomena in question. Recent advances in computer and Internet technology permit even further advances, as it is now possible for the individual sensors in the network to return data in real time and for sensor observation modes (such as sampling frequency) to be easily coordinated. SuomiNet moves beyond the use of the Internet merely for data transmission, it will also use the Internet to coordinate sensors. Hence, the opportunity is presented to develop a national geophysical instrument yielding synchronous data of previously unobtainable timeliness and quality. The resulting data, instrumentation, sensor coordination, and data distribution methods present a unique opportunity for university research and education in the coming decade (Fulker and Ware 1997). SuomiNet has considerable potential to stimulate interdisciplinary research, an important and difficult goal for contemporary science (Metzger and Zare 1999). Examples of potential interdisciplinary science applications for SuomiNet data are described below.

\section{1) Coastal meteorology}

Development of methods for estimation of PW (precipitable water) from buoy-based GPS data is planned by SuomiNet participants at the Scripps Institution of Oceanography. By doing so, they aim to improve the accuracy of GPS buoy positioning, which, combined with underwater acoustic ranging, is used to measure seafloor crustal motion (Spiess et al. 1998). GPS sensing of moisture from buoys holds promise for other applications. For example, buoys moored offshore from the west coast of the United States could provide data that are valuable for coastal meteorology, and drifting buoys with satellite links could provide moisture data for mesoscale (and global) modeling research. Buoy-based GPS sensing could also provide TEC data for global ionospheric modeling research, as well as ocean current and water temperature data for El Niño, tropical cyclone, and climate-related research. As part of SuomiNet, GPS systems will be installed and operated on moored buoy systems located offshore from California and Hawaii. The buoys will be connected via radio modem to the Internet, demonstrating the use of GPS observations from buoys for coastal meteorological research applications. Recognizing the potential of SuomiNet for coastal meteorology and oceanography, participating universities are planning to establish a number of SuomiNet sites in coastal regions.

\section{2) Hydrology}

A major report, "Opportunities in the Hydrologic Sciences" (National Research Council 1991), noted that hydrology is a data-poor science. In particular, atmospheric analyses interpolate and extrapolate radiosonde measurements from coarsely and irregularly spaced land locations, with inadequate spatial and temporal resolution, to represent small-scale hydrological processes (Roads et al. 1994). The availability of distributed, accurate, timely, GPS-sensed atmospheric moisture data on a continental scale is expected to stimulate rapid advancement in hydrology. These data can be assimilated into mesoscale models along with other data for use in estimating four-dimensional water vapor fields, allowing estimation of water vapor flux into watershed regions, and on continental scales. In addition, great potential exists for improving aircraft and satellite-based radiometric data by correcting for atmospheric moisture effects using SuomiNet data. The resultant improvements in remotely sensed surface temperatures should yield significantly improved estimates of sensible heat flux and evapotranspiration.

Recognizing the value of improved atmospheric moisture data for hydrology, participating hydrologists have registered SuomiNet sites in experimental watersheds maintained and operated by the Agricul- 
tural Research Service (ARS) of the U.S. Department of Agriculture. These watersheds have been heavily instrumented with rain gauges, soil moisture, stream flow (flumes), and other hydrological and atmospheric sensors (e.g., Post et al. 1998). The ARS, working closely with universities and research institutions, operates long-term experimental watersheds across the country and has on-site staff to maintain instruments and collect data. Research goals include improved understanding of the coupling of atmospheric and surface parameters in the hydrological cycle, improved modeling, and prediction of stream flow variability and flooding in individual watersheds and on regional and continental scales. Information on the ARS experimental watersheds is available via hydrolab.arsusda.gov/wde/arswater.html.

\section{3) Regional climatology}

The sensitivity of ground-based (and space-based) GPS data to regional and global climate change was demonstrated in global climate model simulations by Yuan et al. (1993) and by Stevens (1999). Major advantages of these data for climatology are their allweather availability and long-term stability without calibration. SuomiNet will provide continuous PW estimates from 100 sites distributed across the United States with better than 2-mm accuracy. In addition, once the appropriate variational methods have been developed, slant GPS delays can be directly assimilated into mesoscale models. Chen and Herring (1997) compare slant delays in microwave (VLBI) signals at low elevation angles with results from ray tracing through mesoscale models. The results show strong coherence, but distinct differences are also evident, implying that VLBI (and GPS) slant delays can be used to improve three-dimensional moisture (and pressure) fields modeled using radiosonde data alone. Similar results for GPS-sensed PW were reported by Kuo et al. (1996) and Businger et al. (1996).

Regional climate research is likely to benefit from improved moisture field definition. For example, Min and Schubert (1997) studied the climate signal in regional moisture fluxes derived from global analyses, finding PW anomalies associated with extreme climate conditions (major drought and flood) in the Great Plains of the central United States. However, they found that the moisture flux estimates from three major global analyses disagreed by as much as $25 \%$ and concluded that inadequate definition of moisture fields in the models is responsible for a major part of this disagreement. GPS-sensed moisture data are ex- pected to be useful for the GEWEX Continental Scale International Project designed to improve understanding of large-scale hydrological cycles (Schaake and Coughlan 1991; www.ogp.noaa.gov/gcip). In particular, the nocturnal Great Plains low-level jet (LLJ), which accounts for approximately one-third of all moisture transport into the continental United States (Helfand and Schubert 1995), extends from near Little Rock, Arkansas, to Amarillo, Texas, and from the Gulf of Mexico to the northern Great Plains/Midwest. Continuous PW data from SuomiNet sites, especially in the Texas-Oklahoma region, should substantially improve the definition of the LLJ moisture field.

\section{4) GROUND TRUTH FOR SATELLITE RADIOMETRY}

Microwave and infrared satellite radiometers are widely used as nadir sensors of atmospheric water vapor [e.g., Geostationary Operational Environmental Satellite and Television Infrared Observation Satellite Operational Vertical Sounder water vapor sensors described by Menzel et al. (1998) and Stankov (1998)]. These satellite systems provide valuable water vapor measurements over oceans where atmospheric data are otherwise scarce. However, satellite radiometers are less accurate for sensing tropospheric water vapor over land, particularly during cloudy conditions. High-resolution four-dimensional water vapor fields based on SuomiNet data will provide ground truth for comparison with satellite-sensed water vapor over North America. Potentially, improved understanding of algorithms and methods for satellite radiometer observations over land could result, leading to improved satellite sensing of water vapor over poorly instrumented land areas.

\section{5) TOPOGRAPHIC SAR CORRECTIONS}

Signal delays induced by atmospheric moisture can significantly degrade interferometric synthetic aperture radar (SAR) sensitivity to crustal deformation or topography. The method combines time-sequenced observations from aircraft or satellites to produce high-resolution images that are sensitive to earth topography and its deformation in time (Massonnet et al. 1993) and to refractivity changes in the troposphere. However, the method cannot differentiate between a signal delay caused, for example, by water vapor heterogeneities in the atmosphere and earth surface deformations. The high temporal sampling characteristics of GPS observations can be used to complement the high spatial resolution of the interferometric SAR images. The GPS observations can be used to deter- 
mine the long wavelength atmospheric signal in the interferometric SAR images and consequently correct these images in deformation studies (Zebker et al. 1997). If there is no surface deformation during the time interval of data acquisitions, SAR imagery can be used to fill spatial gaps in water vapor observations by GPS receivers (Hanssen et al. 1999). Potentially, a combination of SAR and GPS technology could provide accurate high-resolution $(\sim 10 \mathrm{~m})$ moisture data for microscale research, including studies of severe weather, convection, and downbursts. In summary, SuomiNet could significantly increase the impact of SAR interferometric imaging in solid-earth and atmospheric research.

6) IONOSPHERIC SIGNATURES OF GEOPHYSICAL EVENTS

SuomiNet data may contain detectable ionospheric gravity wave signals generated by a variety of geophysical and artificial sources. Included are earthquakes (Calais and Minster 1995); volcanoes (Kanamori 1998); tsunamis (Najita et al. 1974); tornadoes and severe storms (Bedard 1998); transient luminous events, including sprites, jets, and elves (Marshall et al. 1998; Pasko et al. 1997; Lyons et al. 1998; Uppenbrink 1999); meteors, meteorites, and space debris (Bedard and Bloemker 1997); and rocket launches (Calais and Minster 1996). Sampling parameters of SuomiNet GPS receivers can be coordinated using IDD, allowing the network to be "tuned" on a local, regional, or national scale for optimum sensitivity to specific ionospheric events. For example, by "turning up" the sampling frequency in specific regions at specific times, SuomiNet could observe ionospheric signals related to geomagnetic storms; ExB; gravity-acoustic waves generated by jet streams, severe storms and their interactions with topography; and other geophysical events.

\section{7) ATMOSPHERIC CHEMISTRY}

Improved estimates of water vapor flux are expected when GPS-sensed moisture data are properly assimilated into meteorological models. Water vapor flux is useful for modeling of dispersion and chemical processes associated with trace gases, pollutants, water vapor, and aerosols. After SuomiNet has been established, university researchers may consider adding other sensors at all (or a subset of) SuomiNet sites. For example, hydroxyl, ozone, fluorocarbon, carbon monoxide, sulfate, or nitrate sensors (e.g., Comes et al. 1997; Davis et al. 1997) could be included at SuomiNet sites, as appropriate. These sensors, coor- dinated via IDD, could be used for local, regional, and continental atmospheric chemistry studies.

\section{8) Astronomy}

On 27 August 1998, an extremely intense gamma ray flare passed through the solar system, rapidly ionizing the exposed part of the earth's nightside upper atmosphere, producing ionization levels usually found only during daytime (hail.stanford.edu/gammaray.html). This gamma ray flare originated at a faint X-ray star, located in the distant reaches of our galaxy, some 23000 light years away. Similar events could be easily detected in GPS observations of TEC. This example illustrates the potential for SuomiNet in unforeseen interdisciplinary research opportunities.

\section{e. Other GPS networks}

SuomiNet will be one of many GPS networks worldwide, and it will not be the only one used to measure characteristics of the atmosphere. However, SuomiNet will provide unique real-time atmospheric sensing capability over the United States. SuomiNet is designed to stimulate university participation in atmospheric remote sensing activities made possible by GPS.

We wish to stress this optimization characteristic. Sensor networks often are designed to test a particular set of hypotheses, in which case theoretical analyses and simulations can be employed to rationalize a particular sensor configuration. In contrast, SuomiNet will support an extraordinarily broad and interdisciplinary set of studies on poorly observed, characterized, or understood atmospheric features. Therefore, we have not attempted to optimize sensor locations to support specific studies but have chosen a strategy that optimizes student and faculty participation in an emerging domain of atmospheric measurement, one that promises new knowledge, leading to new operational regimes. We think it is critical for the education and research community, broadly defined, to be involved immediately in such advances. In order to maximize the scope of scientific studies that can be undertaken by SuomiNet participants and other investigators, we will seek bidirectional, real-time data exchange agreements with the operators of other high quality GPS networks that exist or are being planned, including the following.

- In North America, various agencies have sponsored the establishment and operation of GPS networks for scientific research, navigation, and engineering. Examples include the Southern California Inte- 
grated GPS Network (milhouse.jpl.nasa.gov); the Coordinated Reference System (www.ngs.noaa.gov/ CORS/cors-data.html); and a central U.S. network established by the National Oceanic and Atmospheric Administration with assistance from UNAVCO and universities to demonstrate the value of GPS-sensed PW data for weather modeling and forecasting (www-dd.fsl.noaa.gov/ gps.html). Other North American GPS networks are described by Showstack (1998).

- In Japan, the world's largest array of 1000 GPS stations was established for earthquake hazard research and mitigation (Fig. 9; mekira.gsi-mc.go.jp). Applications for this network have been expanded to include meteorological, climate, and ionospheric research.

- In Europe, scores of continuous GPS stations have been established for weather, climate, and ionospheric research (Emardson et al. 1998; metix.nottingham.ac.uk/wavefron/index.html).

- Globally, the IGS has coordinated the establishment and operation of a global GPS network including several hundred stations. The original focus of the IGS was geodesy, but its focus has expanded to include ionospheric, tropospheric, sea level, and glo-

\section{One of 1,000 Japanese GPS Network Sites}

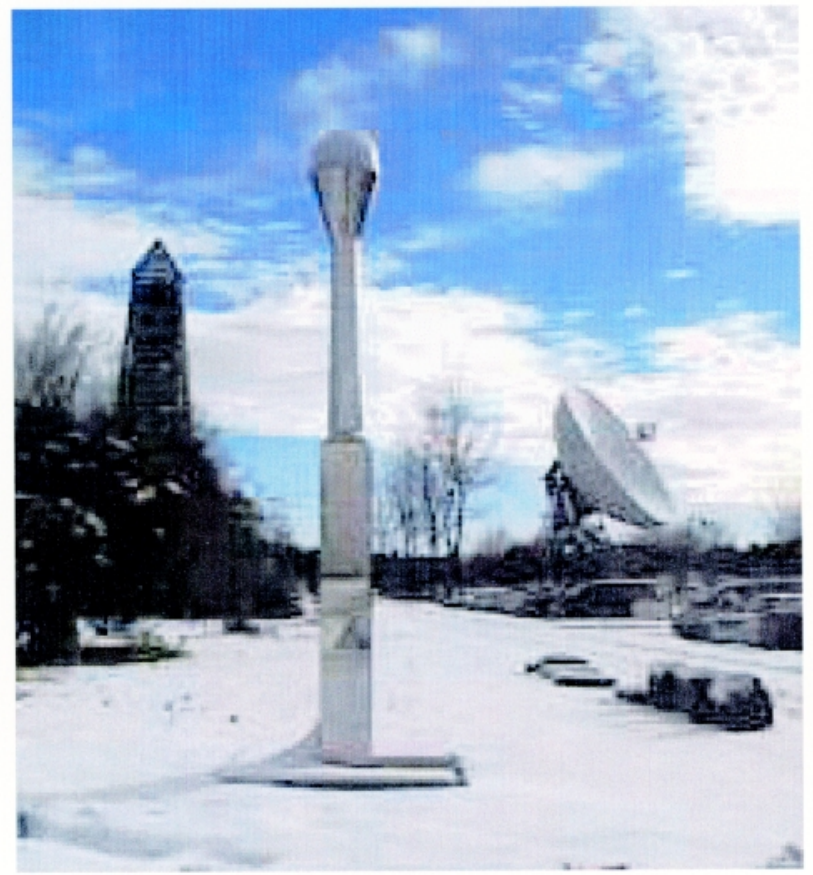

FIG. 9. GPS network sites in Japan are housed in 5-m tall stainless steel towers, as shown. The sites are maintained by private companies under contract; communications are provided by telephone. bal change applications (igscb.jpl.nasa.gov/ projects/projindex.html).

- There are many opportunities for complementary applications of SuomiNet and other GPS networks. For example, real-time PW and TEC contour maps shown in Figs. 4 and 8 use data from a combination of agency and university sites. SuomiNet, although focused primarily on university sites and users, will also coordinate with other networks and users where appropriate.

\section{University participation}

Universities have signed up to establish more than 100 SuomiNet sites (via www.unidata.ucar.edu/ suomi-net). A majority of these sites are located in the interior of the continental United States. However, a variety of other environments are registered including arctic coastal, tropical coastal, island, buoy, and tropical buoy sites. In addition, SuomiNet sites are registered by hydrologists for collaborative watershed research, and by oceanographic research institutions. Overall, the variety of site environments and interests registered for SuomiNet demonstrates its broad interdisciplinary research and educational potential as perceived by universities and research institutions.

\section{Description of research instrumentation}

The standard equipment at a SuomiNet site will include a dual-frequency GPS receiver and antenna, surface meteorology (pressure, temperature, and humidity) sensors, a PC configured to run Local Data Manager (LDM) and IDD software and protocols, radio modems for the Internet connection (optional), cabling, equipment housing, and an antenna mount. For atmospheric applications, the GPS antenna will be mounted (in most cases) on the roof of an academic building (Fig. 10).

The GPS receiver, computer, and ancillary equipment will be located within the building. For atmospheric and geodetic applications, a geologically stable site location away from buildings and multipath reflectors is needed (Figs. 11 and 12). In this case, radio modems, an enclosure for security and protection from the weather, and a stable monument may be installed. Site and monument construction are the responsibility of participants having geodetic research 
and education interests. The GPS receiver, antenna, surface meteorological sensors, and computer will be specified and purchased by UCAR using NSF funds. Site installation, auxiliary equipment, Internet connection, and five years of maintenance will be provided as cost share by participating universities. The UNAVCO facility will provide technical advice and assistance regarding equipment, site construction, and monumentation.

The principal SuomiNet functions including observation, communication and analysis of GPS data, sensor coordination, data product distribution, and data management are described below.

\section{a. Data observation}

Participating universities and research institutions will establish GPS receivers and ancillary equipment at nationally distributed sites. Assistance in GPS equipment specification, procurement, testing, installation, maintenance, and data communication will be provided by the UNAVCO facility (sponsored by the NSF and NASA to develop and support GPS applications in geosciences). Web-based materials already in place will be augmented to assist in these activities. The UNAVCO facility has extensive experience in GPS equipment testing and procurement; in the development, installation, and operation of continuous GPS stations; and in GPS data management (www.unavco.ucar.edu).

\section{b. Data communication, data product distribution, and station coordination}

These activities will be accomplished using IDD, the system that has evolved as the primary means of real-time data distribution by Unidata and its approximately 150 university users. It uses LDM software and protocols (www.unidata.ucar.edu/packages/ldm) and the Internet. The real-time data usage heritage that eventually led to IDD is described by Suomi et al. (1983). The current IDD is a distributed system comprising campus-based LDMs, each of which implements a "push" protocol for rapidly relaying data from neighbor to neighbor, even in the presence of network congestion. Methods based on more than a decade of continuous experience in real-time data distribution are embodied in IDD, including the capability for station coordination.

Each SuomiNet site will include a computer configured to receive executable code via IDD. This will allow for coordination of sensor parameters at all, or any subset of, SuomiNet sites. In this manner, SuomiNet sites can be coordinated for specific observations on local, regional, and continental scales. For example, the sampling frequency of SuomiNet GPS receivers could be adjusted to $1 \mathrm{~Hz}$ or higher to optimize sensitivity to scintillations generated by boundary layer turbulence in the neutral atmosphere, or to look for ionospheric effects associated with meteor showers, geomagnetic storms, and upper-stratospheric/ mesospheric disturbances including sprites, jets, and elves. A condition for participation in SuomiNet is that all SuomiNet data must be made freely available via IDD in real time.

\section{c. Data analysis}

This activity will be carried out at UCAR using well-established automated procedures. Initially, raw GPS data from all SuomiNet sites will be collected and processed into water vapor and TEC data products. UCAR has been providing real-time GPS-sensed PW, TEC, and related data products in real time via the Web since 1995. Examples of real-time PW and TEC data products are shown in Figs. 4 and 8. Any university

\section{Antenna Mount for Atmospheric Applications}

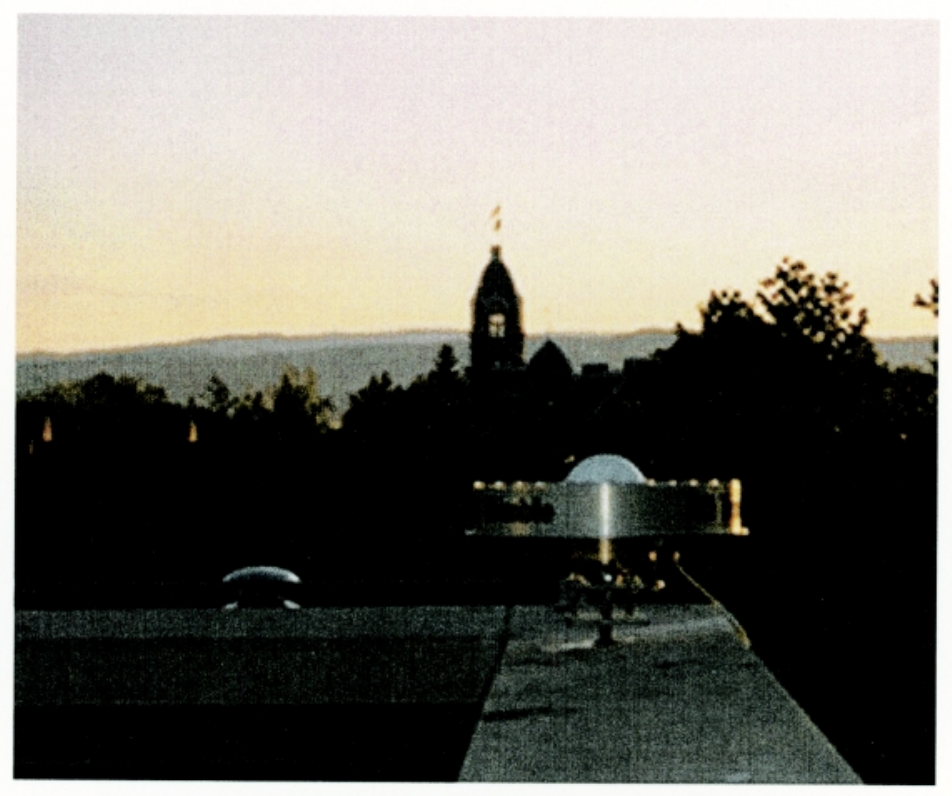

FIG. 10. GPS choke ring antenna at Central Washington University. 
will be able to access SuomiNet data at any level ranging from raw data to derived data products, and to make their own data products available (e.g., PW, SW, TEC, mesoscale or ionospheric model outputs, moisture flux, geodetic coordinates, etc.) using the IDD system.

Universities will be able to set up their own data collection and analysis activities and to provide additional data products. For instance, "sky plots" of atmospheric slant delay are currently provided by the Massachusetts Institute of Technology on a daily basis from networks in California and Asia (bowie.mit.edu/ tah). University groups could provide real-time maps showing ionospheric and tropospheric features causing scintillations, moisture flux into specific watersheds, strong moisture gradients associated with tornado hazards, etc. Thus, interested universities will have opportunities to develop their own programs to use SuomiNet data or derived products for a variety of atmospheric and related research and education activities.

\section{Monument and Antenna Mount for Atmospheric and Geodetic Applications}

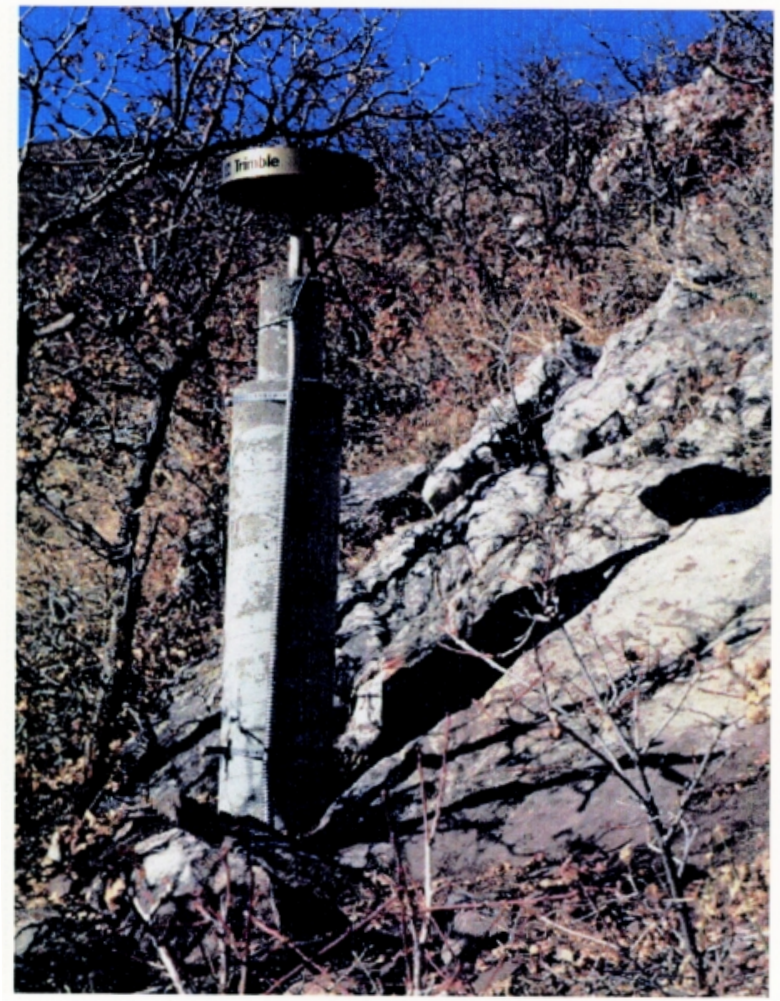

FIG. 11. GPS antenna and monument (University of Utah).

\section{d. Data management}

This activity will be carried out by the UNAVCO facility using its existing online data management and archiving system including its data search, geographic mapping, and display system. To ensure ready availability of data and data products to the atmospheric community, Unidata will provide real-time access via IDD. Short- and long-term atmospheric data management and archiving will be provided by existing UCAR systems (such as www.scd.ucar.edu/dss), as appropriate. In addition, UNAVCO's seamless data archive (www.unavco.ucar.edu/data/\#gsac) could be expanded to include atmospheric data archives at other university and agency sites.

\section{SuomiNet status}

The NSF has decided to fund SuomiNet. Online registration for participation remains open (see the Web site: www.unidata.ucar.edu/suominet). If demand exceeds resources, SuomiNet sites will be selected to achieve broad geographic coverage and gain a large, diverse set of participating institutions, each with applications that are scientifically and educationally compelling.

\section{Atmospheric and Geodetic Installation}

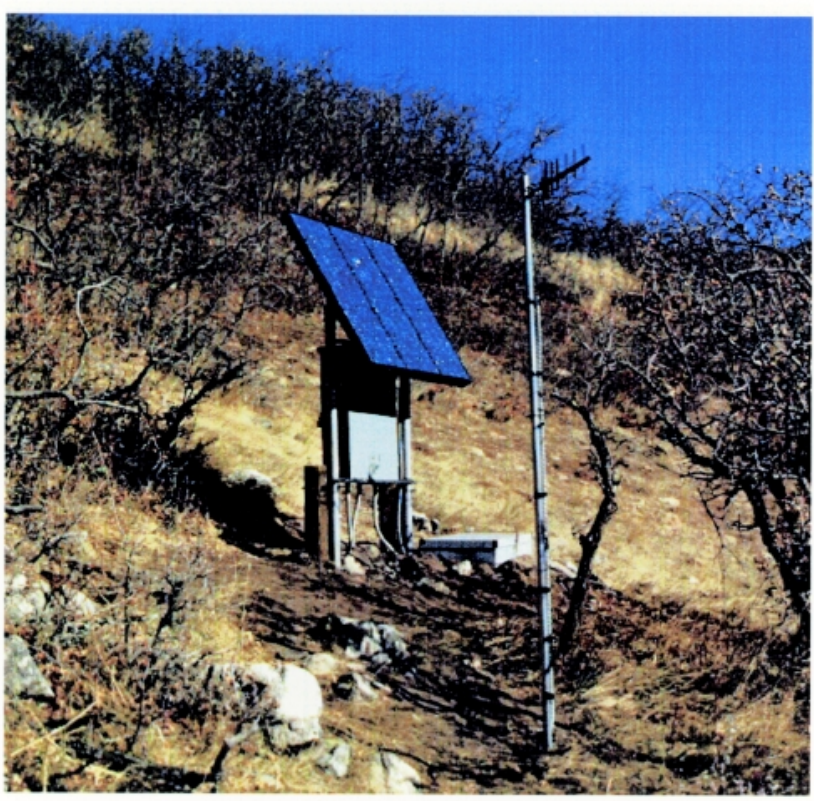

FIG. 12. GPS receiver, solar power, and telemetry equipment (University of Utah). 


\section{Conclusions}

SuomiNet, a real-time national GPS network for atmospheric sensing, is being established. Similar networks are being established or planned in a number of countries around the world. The resulting continuous, accurate, all-weather, global real-time GPS networks will provide a major stimulus to atmospheric research. Research topics for the lower atmosphere include mesoscale modeling and data assimilation, severe weather, precipitation, cloud dynamics, regional climate, hydrology, modeling, and prediction of severe weather. In the upper atmosphere, research topics include modeling and prediction of space weather, detection, and forecasting of low-latitude ionospheric scintillation activity and geomagnetic storm effects at ionospheric midlatitudes, and detection of ionospheric effects induced by a variety of geophysical events. Real-time GPS data also have potential applications in coastal meteorology, satellite radiometry, and boundary layer turbulence. It is important that national real-time GPS networks are coordinated to use common data formats and exchange protocols. This will ensure that the exciting scientific and operational potential of real-time GPS networks is fully realized.

Acknowledgments. Support for the preparation of this article was provided by the National Science Foundation (Grants EAR9840963 and ATM-9843214), UCAR, Unidata, and UNAVCO.

\section{References}

Aarons, J., 1997: Global positioning system phase fluctuations at auroral latitudes. J. Geophys. Res., 102, 17 219-17 231.

Basu, S., and S. Basu, 1981: Equatorial scintilations-A review. J. Atmos. Terr. Phys., 43, 473.

Beach, T., M. Kelley, P. Kintner, and C. Miller, 1997: Total electron content variation due to nonclassical traveling ionospheric disturbances: Theory and Global Positioning System observations. J. Geophys. Res., 102, 7279-7292.

Bedard, A., 1998: Infrasonic detection of severe weather. Preprints, 19th Conf. on Severe Local Storms. Minneapolis, MN, Amer. Meteor. Soc., 218-221.

_ , and R. Bloemker, 1997: Detection of space debris and meteor impacts using atmospheric infrasound. Proc. SPIE, 3116, 32-48.

Bevis, M., S. Businger, T. Herring, C. Rocken, R. Anthes, and R. Ware, 1992: GPS meteorology: Remote sensing of atmospheric water vapor using the Global Positioning System. $J$. Geophys. Res., 97, 15 787-15801.

,,-- S. Chiswell, T. Herring, R. Anthes, C. Rocken, and R. Ware, 1994: GPS meteorology: Mapping zenith wet delays onto precipitable water. J. Appl. Meteor., 33, 379-386.
Braun, J., C. Rocken, and R. Ware, 1999: Operating a dense LI GPS netowrk for atmospheric sensing. Eos, Trans. Amer. Geophys. Union, 80, G12A-09.

Businger, S., and Coauthors, 1996: The promise of GPS in atmospheric monitoring. Bull. Amer. Meteor. Soc., 77, 5-18.

Calais, E., and J. Minster, 1995: GPS detection of ionospheric perturbations following the January 17, 1994, Northridge earthquake. Geophys. Res. Lett., 22, 1045-1048.

- , and — 1996: GPS detection of ionospheric perturbations following a space shuttle ascent. Geophys. Res. Lett., 23, 1897-1900.

Carpenter, R., Jr., and Coauthors, 1998: Storm-scale NWP for commercial aviation: Results from real-time operational tests in 1996-1997. Preprints, 12th Conf. on Numerical Weather Prediction, Phoenix, AZ, Amer. Meteor. Soc., 213-216.

Chen, G., and T. Herring, 1997: Effects of atmospheric azimuthal asymmetry on the analysis of space geodetic data. J. Geophys. Res., 102, 20 489-20 502.

Comes, F., O. Forberich, and J. Walter, 1997: OH field measurements: A critical input into model calculations on atmospheric chemistry. J. Atmos. Sci., 54, 1886-1894.

Cotton, W., G. Thompson, and R. Mielke Jr., 1994: Real-time mesoscale prediction on workstations. Bull. Amer. Meteor. Soc., 75, 349-362.

Crook, N., 1996: Sensitivity of moist convection forced by boundary layer processes to low-level thermodynamic fields. Mon. Wea. Rev., 124, 1767-1785.

Davis, J., G. Elgered, A. Niell, and C. Kuehn, 1993: Ground-based measurement of gradients in the "wet" radio refractivity of air. Radio Sci., 28, 1003-1018.

Davis, W., J. Thorp, and R. Lee, 1997: Variability of $\mathrm{SO}_{4}$, total sulfate, $\mathrm{NO}_{3}$, and total nitrate scavenging ratios for the Frontal Boundary Study. J. Appl. Meteor., 36, 792-817.

Dixon, T., 1991: An introduction to the Global Positioning System and some geological applications. Rev. Geophys., 29, 249-276.

Domenico, B., S. Bates, and D. Fulker, 1994: Unidata Internet Data Distribution (IDD). Preprints, 10th Int. Conf. on Interactive Information and Processing Systems for Meteorology, Oceanography, and Hydrology, Dallas, TX, Amer. Meteor. Soc., J15-J20.

Droegemeier, K., J. Zong, K. Brewster, T. Crum, H. Edmon, D. Fulker, L. Miller, R. Rew, and J. Martin, 1999: The explicit numerical prediction of an intense hailstorm using WSR-88D observations: The need for real-time access to level II data and plans for a prototype acquisition system. Preprints, 15th Int. Conf. on Interactive Information and Processing Systems (IIPS) for Meteorology, Oceanography, and Hydrology, Dallas, TX, Amer. Meteor Soc., 295-299.

Duan, J., and Coauthors, 1996: GPS meteorology: Direct estimation of the absolute value of precipitable water vapor. J. Appl. Meteor., 35, 830-838.

Elosegui, P., A. Rius, J. Davis, G. Ruffini, S. Keihm, and B. Burki, 1998: An experiment for estimation of the spatial and temporal variations of water vapor using GPS and WVR data. Phys. Chem. Earth, 23, 125-130.

—, J. Davis, L. Gradinarsky, G. Elgered, J. Johansson, D. Tahmoush, and A. Ruis, 1999: Sensing atmospheric structure using small scale space geodetic networks. Geophys. Res. Lett., 26, 2445-2448 
Emanuel, K., and Coauthors, 1995: Report of the First Prospectus Development Team of the U.S. Weather Research Program to NOAA and the NSF. Bull. Amer. Meteor. Soc., 76, 1194-1208.

Emardson, T., G. Elgered, and J. Johanssson, 1998: Three months of continuous monitoring of atmospheric water vapor with a network of GPS receivers. J. Geophys. Res., 103, 1807-1820.

Fang, P., M. Bevis, Y. Bock, S. Gutman, and D. Wolfe, 1998: GPS meteorology: Reducing systematic errors in geodetic estimates for zenith delay. Geophys. Res. Lett., 25, 3583-3596.

Fremouw, E., L. Leadabrand, R. Livingston, M. Cousins, C. Rino, B. Fair, and R. Long, 1978: Early results from the DNA wideband satellite experiment-Complex signal scintillation. Radio Sci., 13, 167.

Fritts, D., and G. Nastrom, 1992: Sources of mesoscale variability of gravity waves. Part II: Frontal, convective, and jet stream excitation. J. Atmos. Sci., 49, 111-127.

Fulker, D., and R. Ware, 1997: Real-time GPS network facilitates geophysical studies. Eos, Trans. Amer. Geophys. Union, 78, 582.

Guo, Y.-R., Y.-H. Kuo, J. Dudhia, and D. Parsons, 2000: Fourdimensional variational data assimilation of heterogeneous mesoscale observations for a strong convective case. Mon. Wea. Rev., 128, 619-643.

Hager, B., R. King, and M. Murray, 1991: Measurement of crustal deformation using the Global Positioning System. Annu. Rev. Earth Planet. Sci., 19, 351-382.

Hanssen, R., T. Weckworth, H. Zebker, and R. Klees, 1999: Highresolution water vapor mapping from interferometric radar measurements. Science, 283, 1297-1299.

Helfand, H., and S. Schubert, 1995: Climatology of the simulated Great Plains low-level jet and its contribution to the continental moisture budget of the United States. J. Climate, 8, 784806.

Hernandez-Pajares, M., J. M. Juan, J. Sanz, and J. G. Sole, 1998: Global observation of the ionospheric electronic response to solar events using ground and LEO GPS data. J. Geophys. Res., 103, 20 789-20 796.

Herring, T., and S. Shimada, 1998: Estimating spatial variations in atmospheric delays using GPS. Proc. Conf. on GPS Meteorology, Tsukuba, Japan. [Available from http://bowie.mit.edu/ $\sim$ tah.]

Ho, C., A. Mannucci, U. Lindqwister, S. Pi, and B. Tsuritani, 1996: Global ionosphere perturbations monitored by the worldwide GPS network. Geophys. Res. Lett., 23, 3219-3222.

Holmlund, K., 1998: The utilization of statistical properties of satellite-derived atmospheric motion vectors to derive quality indicators. Wea. Forecasting, 13, 1093-1104.

Horel, J., and C. Gibson, 1994: Analysis and simulation of a winter storm over Utah. Wea. Forecasting, 9, 479-507.

Howe, B., K. Runciman, and J. Secan, 1998: Tomography of the ionosphere: Four-dimensional simulations. Radio Sci., 33, 109-128.

Iwabuchi, T., I. Naito, and N. Mannoji, 1999: Behavior of GPS retrieved precipitable water vapor over the Japanese islands. J. Meteor. Soc. Japan, submitted.

Juan, J. M., A. Rius, M. Hernandes-Pajares, and J. Sanz, 1997: A two-layer model of the ionosphere using Global Positioning System data. Geophys. Res. Lett., 24, 393-396.

Kanamori, H., 1998: Shaking without quaking. Science, 279, 2063-2064.
Kelley, M., D. Kotsikopoulos, T. Beach, and D. Hysell, 1996: Simultaneous Global Positioning System and radar observations of equatorial spread F at Kwajalein. J. Geophys. Res., 101, 2333-2341.

Kuo, Y.-H., X. Zou, and Y.-R. Guo, 1996: Variational assimilation of precipitable water using a nonhydrostatic mesoscale adjoint model. Mon. Wea. Rev., 124, 122-147.

Li, J., and J. Mao, 1998: The approach to remote sensing of water vapor based on GPS and linear regression of Tm in the eastern region of China. Acta Meteor. Sin., 12, 450-458.

Liou, Y.-A., 2000: Precipitable water observed by ground-based GPS receivers. Terr. Atmos. Oceanic Sci., in press.

Lyons, W., T. Nelson, E. Williams, J. Cramer, and T. Turner, 1998: Enhanced positive cloud-to-ground lightning in thunderstorms ingesting smoke from fires. Science, 282, 77-80.

MacDonald, A., and Y. Xie, 2000: On the use of slant observations from GPS to diagnose three-dimensional water vapor using 3DVAR. Preprints, Fourth Symp. on Integrated Observing Systems, Long Beach, CA, Amer. Meteor. Soc., 62-73.

Marshall, L., L. Hale, C. Croskey, and W. Lyons, 1998: Electromagnetics of sprite-and elve-associated sferics. $J$. Atmos. Solar Terr. Phys., 60, 771-786.

Mass, C., and Y.-H. Kuo, 1998: Regional real-time numerical weather prediction: Current status and future potential. Bull. Amer. Meteor. Soc., 79, 253-263.

Massonnet, D., M. Rossi, C. Carmona, F. Adagna, B. Peltzer, K. Feigl, and T. Rabaute, 1993: The displacement field of the Landers earthquake mapped by radar interferometry. Nature, 364, 138-142.

McPherson, R., E. Kalnay, and S. Lord, 1997: The potential role of GPS/MET observations in operational numerical weather prediction. The Global Positioning System for the Geosciences. NRC Rep. 9254, National Academy Press, 111-113. [Available online at http://www.nap.edu/catalog/9254.html.]

Meertens, C., J. Braun, D. Mencin, C. Conquest, L. Estey, T. Dixon, and D. Dzurisin, 1998: A new GPS system for imaging volcanoes, faults and storms, Eos, Trans. Amer. Geophys. Union, 79, F34.

Menzel, P., F. Holt, T. Schmit, R. Aune, A. Schreiner, G. Wade, and D. Gray, 1998: Application of GOES-8/9 soundings to weather forecasting and nowcasting. Bull. Amer. Meteor. Soc., 79, 2059-2077.

Metzger, N., and R. Zare, 1999: Interdisciplinary research, from belief to reality. Science, 283, 642-643.

Min, W., and S. Schubert, 1997: The climate signal in regional moisture fluxes: A comparison of three global data assimilation prosucts. J. Climate, 10, 2623-2642.

Minami, H., T. Tsuda, Y. Masuda, K. Nishimuta, and Y. Ohno, 1999: Scintillation of satellite broadcasting signals caused by atmospheric turbulence in the troposphere. J. Geophys. Res., submitted.

Murayama, Y., T. Tsuda, and S. Fukao, 1994: Seasonal variation of gravity wave activity in the lower atmosphere observed with the MU radar. J. Geophys. Res., 99, 23 05723069.

Musman, S., J.-M. Jahn, J. LaBelle, and W. Swartz, 1997: Imaging spread-F structures using GPS observations at Alcantara, Brazil. Geophys. Res. Lett., 24, 1703-1706.

Naito, I., Y. Hatanaka, N. Mannoji, R. Ichikawa, S. Shimada, T. Yabuki, H. Tsuji, and T. Tanaka, 1998: Global Position- 
ing System project to improve Japanese weather, earthquake predictions. Eos, Trans. Amer. Geophys. Union, 79, 301-311.

Najita, K., P. Weaver, and P. Yuen, 1974: A tsunami warning system using an ionospheric technique. Proc. IEEE, 62.

Nastrom, G., and D. Fritts, 1992: Sources of mesoscale variability of gravity waves. Part I: Topographic excitation. J. Atmos. Sci., 49, 101-110.

National Research Council, 1991: Opportunities in the Hydrological Sciences. National Academy Press, 348 pp.

— 1998: The Atmospheric Sciences: Entering the Twenty-First Century. National Academy Press, 364 pp.

Niell, A., 1996: Global mapping functions for the atmosphere delay at radio wavelengths. J. Geophys. Res., 101, 3227-3246.

Ohtani, R., and I. Naito, 1998: Comparison of GPS retrieved precipitable water vapor to radiosonde observations over Japan. J. Meteor. Soc. Japan, submitted.

Park, S., and K. Droegemeier, 1996: Sensitivity of 3-D convective storm evolution to water vapor and implications for variational data assimilation. Preprints, 11th Conf. on Numerical Weather Prediction, Norfolk, VA, Amer. Meteor. Soc., 137139.

Pasko, V., U. Inan, T. Bell, and Y. Taranenko, 1997: Sprites produced by quasi-electrostatic heating and ionization in the lower ionosphere. J. Geophys. Res., 102, 4529-4561.

Post, D., G. Grant, and J. Jones, 1998: New developments in ecological hydrology expand research opportunities. Eos, Trans. Amer. Geophys. Union, 79, 517-518.

Rius, A., G. Ruffini, and L. Cucurull, 1997: Improving the vertical resolution of ionospheric tomography with GPS occultations. Geophys. Res. Lett., 24, 2291-2294.

,-- , and A. Romeo, 1998: Analysis of ionospheric electron density distribution from GPS/MET occultations. IEEE Trans. Geosci. Remote Sens., 36, 383-394.

Roads, J., S.-C. Chen, A. Guetter, and K. Georgakakos, 1994: Large-scale aspects of the United States hydrological cycle. Bull. Amer. Meteor. Soc., 75, 1589-1610.

Rocken, C., R. Ware, T. Von Hove, F. Solheim, C. Alber, and J. Johnson, 1993: Sensing atmospheric water vapor with the Global Positioning System. Geophys. Res. Lett., 20, 2631-2634.

_ - T. Van Hove, J. Johnson, F. Solheim, R. Ware, M. Bevis, S. Businger, and S. Chiswell, 1995: GPS storm-GPS sensing of atmospheric water vapor for meteorology. J. Atmos. Oceanic Technol., 12, 468-478.

- _ - , and R. Ware, 1997a: Near real-time sensing of atmospheric water vapor. Geophys. Res. Lett., 24, 3221-3224.

_ , and Coauthors, 1997b: Analysis and validation of GPS/ MET data in the neutral atmosphere. J. Geophys. Res., 102, 29 849-29 866.

Saito, A., S. Fukao, and S. Miyazaki, 1998: High resolution mapping of TEC perturbations with the GSI GPS network over Japan. Geophys. Res. Lett., 25, 3079-3082.

Schaake, J., and M. Coughlan, 1991: GEWEX continental scale international project implementation strategy. Eos, Trans. Amer. Geophys. Union, 72, 592.

Schreiner, W., S. Sokolovskiy, C. Rocken, and D. Hunt, 1999: Analysis and validation of GPS/MET radio occultation data in the ionosphere. Radio Sci., 34, 949-966.

Segall, P., and J. Davis, 1997: GPS applications for geodynamics and earthquake studies. Annu. Rev. Earth Planet. Sci., 25, 301-336.
Showstack, R., 1998: Global positioning station arrays come of age in western North America. Eos, Trans. Amer. Geophys. Union, 79, 517-518.

Solheim, F., J. Vivekanadan, R. Ware, and C. Rocken, 1999: Propagation delays induced in GPS signals by dry air, water vapor, hydrometeors, and other particlates. J. Geophys. Res., 104, 9663-9670.

Speiss, F., C. Chadwell, J. Hildebrand, L. Young, G. Purcell, and H. Dragert, 1998: Precise GPS/acoustic positioning of sea floor reference points for tectonic studies. Phys. Earth Planet. Interiors, 108, 101-112.

Stankov, B., 1998: Multisensor retrieval of atmospheric properties. Bull. Amer. Meteor. Soc., 79, 1835-1854.

Starr, D., and S. Melfi, 1991: The role of water vapor in climate: A strategic plan for the proposed GEWEX Water Vapor Project (GVaP), NASA Conf. Publ. 3120, 50 pp.

Stein, S., and the UNAVCO Steering Committee, 1998: UNAVCO: Supporting Research into Earth Processes and Hazards via High-Precision Geodesy Using the Global Positioning System. University Corporation for Atmospheric Research, 16 pp. [Available online at http://www.unavco.ucar.edu/community/brochure.]

Stevens, M., 1999: Optimal climate signal detection in four dimensions. J. Geophys. Res., 104, 4089-4099.

Stokes, G., and S. Schwartz, 1994: The Atmospheric Radiation Measurement (ARM) program: Programmatic background and design of the cloud and radiation test bed. Bull. Amer. Meteor. Soc., 75, 1201-1221.

Suomi, V., R. Fox, S. Limaye, and W. Smith, 1983: McIDAS III: A modern interactive data access and analysis system. J. Climate Appl. Meteor., 22, 766-778.

Taylor, M., J.-M. Jahn, S. Fukao, and A. Saito, 1998: Possible evidence of gravity wave coupling into the mid-latitude $\mathrm{F}$ region ionosphere during the SEEK campaign. Geophys. Res. Lett., 25, 1801-1804.

Trenberth, K., and C. Guillemot, 1996: Evaluation of the atmospheric moisture and hydrological cycle in the NCEP reanalyses. NCAR Tech. Note TN-430, 98 pp.

Tsuda, T., Y. Murayama, T. Nakamura, R. Vincent, A. Manson, C. Meek, and R. Wilson, 1994: Variations of the gravity wave characteristics with height, season and latitude revealed by comparative observations. J. Atmos. Terr. Phys., 56, 555568 .

_- , and Coauthors, 2000a: GPS meteorology project of Japan, exploring frontiers of geodesy. Earth Planet. Space, in press.

_- M. Nishida, C. Rocken and R. Ware, 2000b: A global morphology of gravity wave activity in the stratosphere revealed with the GPS occultation data (GPS/MET). J. Geophys. Res., in press.

Uppenbrink, J., 1999: Catching sprites by radio. Science, 284, 929.

Ware, R., and Coauthors, 1996: GPS sounding the atmosphere from low earth orbit: Preliminary results. Bull. Amer. Meteor. Soc., 77, 19-40.

— C. Alber, C. Rocken, and F. Solheim, 1997: Sensing integrated water vapor along GPS ray paths. Geophys. Res. Lett., 24, 417-420.

Warner, T., and N. Seaman, 1990: A real-time mesoscale numerical weather prediction system used for research, teaching, and public service at The Pennsylvania State University. Bull. Amer. Meteor. Soc., 71, 792-805. 
Whiteway, J., and A. Carswell, 1995: Lidar observations of gravity in the upper stratosphere over Toronto. J. Geophys. Res., 100, 14 113-14 124.

Wilson, B., A. Mannucci, and C. Edwards, 1995: Subdaily Northern Hemisphere ionospheric maps using an extensive network of GPS receivers. Radio Sci., 30, 639-648.

Xue, M., and Coauthors, 1996: The 1996 CAPS spring operational forecasting period: Real-time storm-scale NWP, Part II: Operational summary and sample cases. Preprints, 11th Conf. on Numerical Weather Prediction, Norfolk, VA, Amer. Meteor. Soc., 297-300.
Yeh, K.-C., and C.-H. Liu, 1982: Radio wave scintillations in the ionosphere. Proc. IEEE, 70, 324.

Yuan, L., R. Anthes, R. Ware, C. Rocken, W. Bonner, M. Bevis, and S. Businger, 1993: Sensing climate change using the Global Positioning System. J. Geophys Res., 98, 14 925-14 937.

Zebker, H., P. Rosen, and S. Hensley, 1997: Atmospheric effects in interferometric synthetic radar surface deformation and topographic maps. J. Geophys. Res., 102, 7547-7563.

Zumberge, J., D. Fulton, and R. Neilan, Eds., 1997: International GPS Service 1996 Annual Report. IGS Central Bureau, Jet Propulsion Laboratory, 119 pp. [Available on line at ftp:// igscb.jpl.nasa.gov/igscb/resource/pubs/ar96.pdf.]

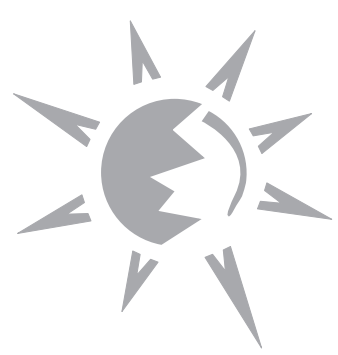

